cultivadores debería esperar hasta la centuria siguiente, con el advenimiento de la dinastía Borbón.

\section{Notas}

1. Sobre la figura de Dionisio de Cardona cf. J.M. López Piñero et al. Diccionario de la ciencia moderna en España. Barcelona, 1983. Su trabajo en el Real Laboratorio Químico analizado por M.M. Rey Bueno \& M.E. Alegre Pérez. Dynamis, 16: 261-290. 1996.
2. Este memorial, que lleva por título Sobre la química, fue presentado al Sumiller de Corps, conde de Benavente, el 9 de agosto de 1694; se conserva en el Archivo General de Palacio (Madrid), sección Administrativa, leg. 429.

Aceptado para su publicación en Junio de 1997

Dirección de la autora. Departamento de Farmacia y Tecnología Farmacéutica. Facultad de Farmacia. Universidad Complutense. 28040 Madrid.

\title{
27. LA CORRESPONDENCIA ENTRE PIERRE ANDRÉ POURRET (1754- 1818) Y PHILIPPE PICOT DE LAPEYROUSE (1744-1818) CONSERVADA EN EL MUSEO DE HISTORIA NATURAL DE PARÍS
}

\author{
Raúl RODRÍGUEZ NOZAL y Cécile MARCHAND
}

La figura del botánico francés P.A. Pourret ha dado lugar a una abundante bibliografía desde la segunda mitad del siglo XIX, producida tanto por autores franceses ${ }^{1}$ como españoles ${ }^{2}$. Recientemente, la vida y la obra de este autor han sido analizadas en tres memorias de licenciatura ${ }^{3}$ y en algunas publicaciones ${ }^{4}$. No obstante, la azarosa existencia de este clérigo narbonense, afincado en España durante una buena parte de su vida, y su aportación a la Botánica no podrán ser del todo desentrañadas hasta que se estudie en profundidad su documentación epistolar, su herbario y se aclare su atribuida obra inédita.

En este sentido, la correspondencia conservada en el Museo de Historia Natural de
París, únicamente citada por E. Timbal-Lagrave aunque no con la exhaustividad que merece, parece una herramienta de extraordinaria utilidad para el estudio de este personaje. En total son veintiocho cartas en francés de P.A. Pourret dirigidas a P.P. de Lapeyrouse, escritas entre mayo de 1777 y junio de 1818, y un soneto, éste en italiano; a pesar del amplio intervalo temporal abarcado, todas ellas fueron redactadas en dos periodos concretos: durante su estancia en Narbona y Breen (1777-1788) y a lo largo de los dos años transcurridos entre su nombramiento como Canónigo de Santiago de Compostela y su muerte (1815-1818). La relación completa de este epistolario es la siguiente: 
1.- Narbonne, 30 de mayo de 1777. Archivo Museo de Historia Natural de París (Archivo M.H.N.P.), leg. 1993, carta 658; 4 págs.

2.- Narbonne, 16 de marzo de 1778. Archivo M.H.N.P., leg. 1993, carta 659; 4 págs.

3.- Narbonne, 6 de junio de 1778. Archivo M.H.N.P., leg. 1993, carta 660; 4 págs.

4.- Narbonne, 13 de julio de 1778. Archivo M.H.N.P., leg. 1993, carta 661; 3 págs. y sobre.

5.- S.l., 25 de julio de 1788. Archivo M.H.N.P., leg. 1993, carta 662; 3 págs. y sobre.

6.- Narbonne, 31 de mayo de 1780. Archivo M.H.N.P., leg. 1993, carta 664; 4 págs.

7.- Paris, 18 de marzo de 1784. Archivo M.H.N.P., leg. 1993, carta 665; 7 págs.

8.- Bar-sur Aube, 16 de julio de 1785. Archivo M.H.N.P., leg. 1993, carta 666; 3 págs.

9.- Brienne, 14 de enero de 1786. Archivo M.H.N.P., leg. 1993, carta 667; 4 págs.

10.- Château de St. Lier, 24 de abril de 1787. Archivo M.H.N.P., leg. 1993, carta 668; 3 págs.

11.- Brienne, s.f. Archivo M.H.N.P., leg. 1993, carta $669 ; 2$ págs. y sobre.

12.- Brienne, 3 de julio de 1787. Archivo M.H.N.P., leg. 1993, carta 670; 3 págs.

13.- Paris, 12 de febrero de 1788. Archivo M.H.N.P., leg. 1993, carta 671; 2 págs. y sobre.

14.- Santiago de Compostela, 1 de [?] de 1816. Archivo M.H.N.P., leg. 1993, carta 672; 8 págs.

15.- Santiago, 14 de febrero de 1816. Archivo M.H.N.P., leg. 1993, carta 673; 8 págs.

16.- Santiago, 23 de abril de 1816. Archivo M.H.N.P., leg. 1993, carta 675; 6 págs.

17.- Santiago, 6 de julio de 1816. Archivo M.H.N.P., leg. 1993, carta 676; 7 págs. y sobre.

18.- Santiago, 3 de septiembre[?] de 1816. Archivo M.H.N.P., leg. 1993, carta 677; 3 págs. y sobre.

19.- Santiago, 20 de octubre de 1816. Archivo M.H.N.P., leg. 1993, carta 678; 4 págs.

20.- Santiago, 18 de noviembre[?] de 1816. Archivo M.H.N.P., leg. 1993, carta 679; 4 págs.

21.- Santiago, 5 de marzo de 1817. Archivo M.H.N.P., leg. 1993, carta 680; 4 págs.

22.- Santiago, 10 de mayo de 1817. Archivo M.H.N.P., leg. 1993, carta 681; 4 págs.

23.- Santiago, 6 de septiembre de 1817. Archivo

M.H.N.P., leg. 1993, carta 682; 5 págs. y sobre.

24.- Santiago, 30 de noviembre de 1817. Archivo

M.H.N.P., leg. 1993, carta 683; 3 págs. y sobre.

25.- Santiago, 26 de enero de 1818. Archivo
M.H.N.P., leg. 1993, carta 683a; 5 págs. y sobre. 26.- Santiago, 28 de marzo de 1818. Archivo M.H.N.P., leg. 1993, carta 674; 4 págs.

27.- Santiago, 20 de abril de 1818. Archivo M.H.N.P., leg. 1993, carta 684; 3 págs. y sobre.

28.- Santiago, 25 de junio de 1818. Archivo M.H.N.P., leg. 1993, carta 685; 7 págs. y sobre. 29.- Sonetto. [ca. 1786]. Archivo M.H.N.P., leg. 1993, doc. 663; 1 pág.

\section{Notas}

1. L. Galibert. Biographie de Pierre-André Pourret. Narbonne, 1856; D. Clos. Pourret et son histoire des cistes. Toulouse, [1858]; E. Timbal-Lagrave. Bull. Soc. Sci. Phys. Nat. Toulouse, 2: 1-149. 1875; S. Pons. Bull. Soc. Bot. France, 40: LXXI-LXXV. 1893; E. Bonnet. Bull. Mus. Hist. Nat. Paris, 6: 278286. 1916; M. Guétrot. Bull. Soc. Bot. France, 78: 434-437. 1931; M. Gard. Bull. Soc. Bot. France, 79: 635-637. 1932.

2. M. Colmeiro. Noticia de los trabajos botánicos del abate Pourret en Francia y España. Madrid, 1891; F. Bellot Rodríguez. Pourret, Colmeiro, Planellas y Antonio Casares Gil lla escuela botánica compostelana). Santiago de Compostela, 1956.

3. R. Rodríguez Nozal. Herbario Pourret: tratamiento informático de la Colección depositada en MAF. Transcripción de las familias Cistaceae y Thymeleaceae. Facultad de Farmacia. Universidad Complutense. Madrid, 1990; I. Muñoz Colomina. Herbario Pourret: Monografía del género Galium. Facultad de Farmacia. Universidad Complutense. Madrid, 1992; O. Álvarez Villaverde. Pedro Andrés Pourret, Canónigo de la S.A.M.Y. de Santiago (Historia de una botánico francés en Compostela). Facultad de Farmacia. Universidad de Santiago. Santiago de Compostela, 1988. 
4. A. Velasco Negueruela. Studia Botanica, 4: 117-121. 1985; M. Laínz. Anales Jard. Bot. Madrid, 45(1): 345-346. 1988; M. Gutiérrez \& C. Navarro. Acta Bot. Malacitana, 14: 193-195. 1989; R. Rodríguez Nozal \& al. Acta Bot. Malacitana, 16(2): 467-468. 1991; I. Muñoz \& al. Webbia, 48: 605-610. 1993; I. Muñoz. Acta Bot. Malacitana, 18: 281-283. 1993; J. Izco \& O. Álvarez Villaverde. Pedro
Andrés Pourret. Un botánico francés canónigo de las catedrales de Ourense y Santiago (1799-1818). Santiago de Compostela, 1996.

Aceptado para su publicación en Junio de 1997

Dirección de los autores: Centre de Recherches Latino-Américaines. Université de Poitiers. 86022Poitiers (Francia). 